\title{
PRACTICAL MEASURES AGAINST SEA SALT PARTICLES FROM AN EXISTING VERTICAL WALL
}

\author{
Masaru Yamashiro ${ }^{1}$, Akinori Yoshida ${ }^{2}$ and Yasuhiro Nishii ${ }^{3}$
}

\begin{abstract}
At Waku fishing port, facing to Japan Sea, in Yamaguchi prefecture, Japan, a vertical type breakwater was constructed in front of the mouth of the port to protect the inside against incoming waves about 10 years ago. Residents in the area have been troubled with heavy seawater spray and much smaller sea salt particles caused at the breakwater by sever waves and strong winds ever since. To reduce the generation of and the damage from the seawater spray and the sea salt particles, three different types of measures were proposed: (a) covering the breakwater with wave dissipating blocks, (b) construction of a low crested offshore breakwater some distance ahead of the breakwater, and (c) construction of an artificial reef some distance ahead of the breakwater. Laboratory experiments using a wave flume with a wind tunnel were conducted to compare the effects of suppressing the water spray generation. The results of the comparative experiments showed that the covering with the wave dissipating blocks (Plan (a)) is the most effective means.
\end{abstract}

Keywords: vertical breakwater; salt damage; sea salt particle; seawater spray; splash; wave dissipating blocks; wind-wave flume

\section{INTRODUCTION}

In Japan, composite or vertical breakwaters are generally used to keep harbors and ports calm by preventing large waves from entering. Violent wave run-ups like a flip-through type wave overtopping, however, are sometimes caused at the vertical front face of the breakwaters by violent incident waves. Consequently, splashes, spray and much smaller sea salt particles are generated in large quantities. Such a large quantity of sea salt particles in particular is diffused landward by the strong wind and causes severe salt damage over a wide area. The problem often happens at many places along the coastline of Japan. Although the effect of wind on the quantity of wave overtopping is somewhat described in the manuals of shore protection structures, e.g. EurOtop Wave Overtopping Manual (2007), Technical Standards in Japan (2002), etc., the influence of the salt water particles on surrounding areas has not been considered in the design of shore protection structures (breakwaters, seawalls, etc.) in general.

Waku Fishing port located in Yamaguchi Prefecture in Japan is one such place and the residents in the area have been troubled by the salt water particles transported from the breakwater located off the port entrance. In the case of this fishing port, the following three plans to cope with such salt damage were proposed: (a) covering the front face of the breakwater with wave dissipating blocks, (b) construction of a low-crested offshore breakwater of wave dissipating blocks in the farther offing, (c) construction of an artificial reef in front of the breakwater.

In this study, to clarify the most effective measure among the proposed three plans, comparative model experiments on the quantity of the splash caused at the front face of each model breakwater were conducted by using a wind-wave flume.

\section{SALT DAMAGE AT WAKU FISHING PORT}

\section{Waku fishing port}

Fig. 1 shows the location of Waku fishing port. The fishing port is located in west part of Japan and is facing to the Japan Sea. An aerial view and a map of the port are shown in Fig. 2 and Fig. 3. This area is a typical small fishing village in Japan. Houses, warehouses, etc. exist densely in the small area immediately behind the small port. In winter, this port is often attacked by large waves because the Japan Sea frequently becomes rough by a seasonal wind. And also this port is sometimes struck by typhoons passing over this area from summer to autumn.

A breakwater was built offshore of the mouth of the port to prevent wave attacks and to keep the port calm. The cross section of the breakwater is shown in Fig. 4. The breakwater (crown height $7.10 \mathrm{~m}$

\footnotetext{
${ }^{1}$ Department of Urban and Environmental Engineering, Faculty of Engineering, Kyushu University, 744 Motooka, Nishi-ku, Fukuoka, 819-0395, Japan

${ }^{2}$ Department of Urban and Environmental Engineering, Faculty of Engineering, Kyushu University, 744 Motooka, Nishi-ku, Fukuoka, 819-0395, Japan

${ }^{3}$ Sanyo Consultants Co., Ltd., 3-4-17 Kyomachi, KokuraKita-ku, Kitakyushu, 802-8534, Japan
} 
on CDL (chart datum level), width $13.10 \mathrm{~m}$ and length $140 \mathrm{~m}$ ) is relatively large and is very effective to prevent severe incoming waves. However, when the large waves attack the breakwater, the violent wave run-up occurs frequently, and a large quantity of the spray is transported landward by a strong wind.

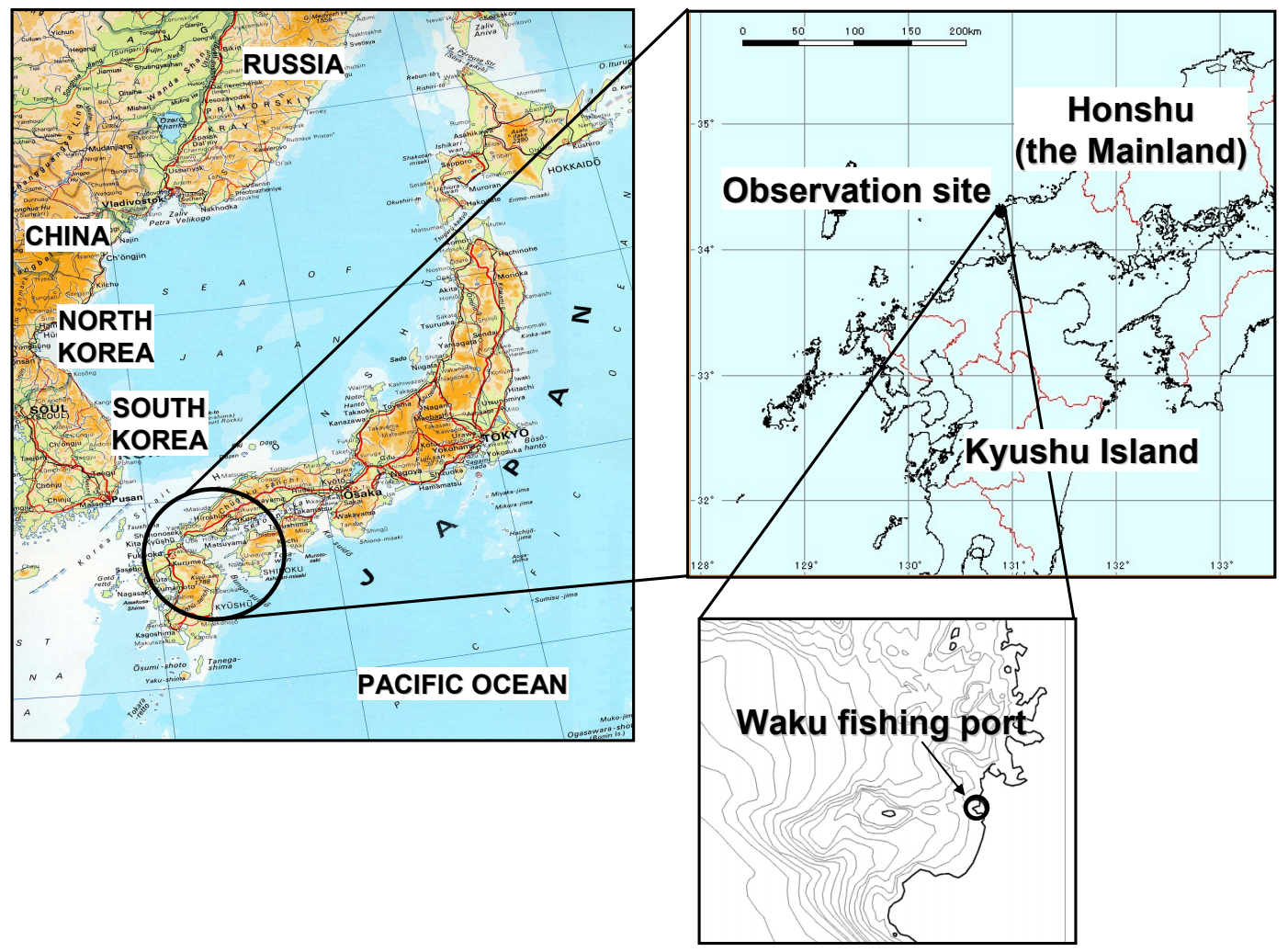

Figure 1. Location of Waku fishing port.

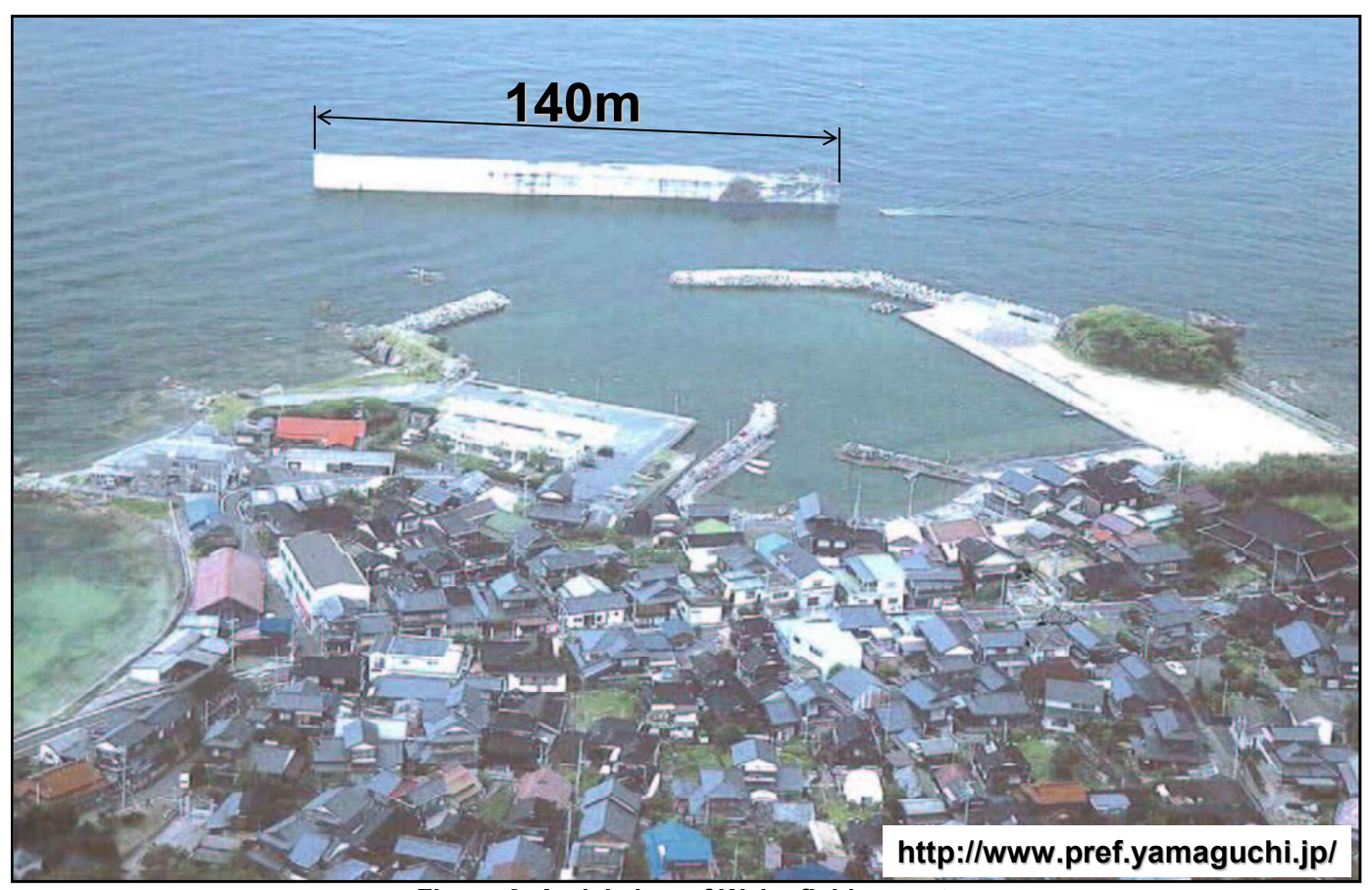

Figure 2. Aerial view of Waku fishing port. 


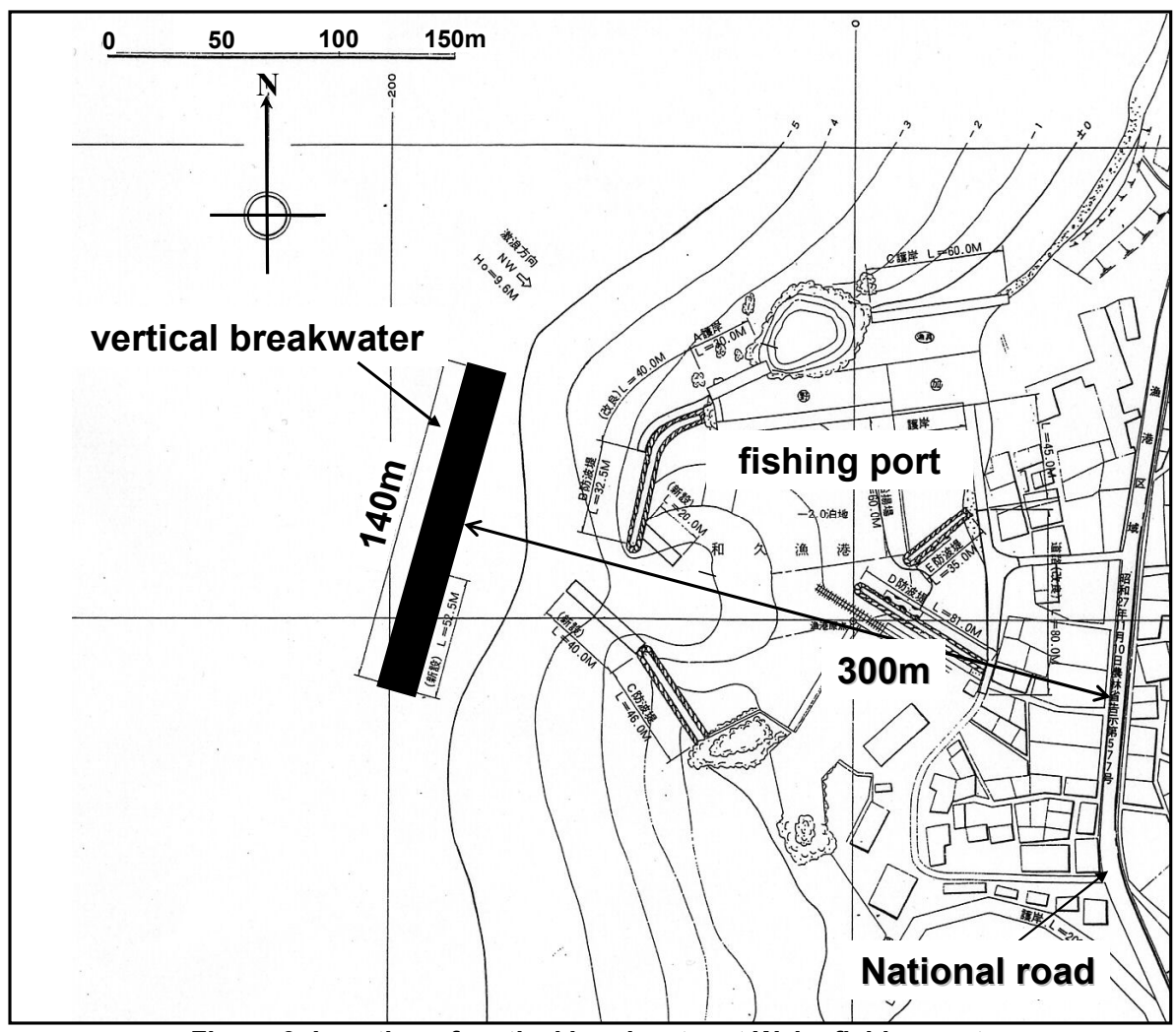

Figure 3. Location of vertical breakwater at Waku fishing port.

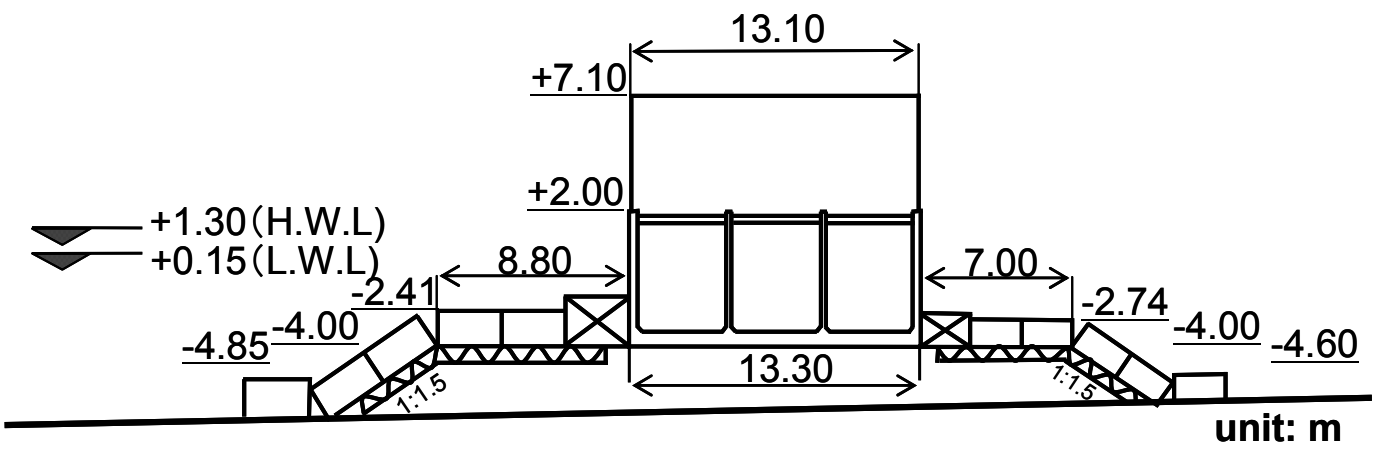

Figure 4. Cross section of existing vertical breakwater at Waku fishing port.

\section{Seawater spray generated at a vertical breakwater}

At the fishing port, the field observations on landward transportation of spray generated at the vertical breakwater were conducted in the winter season (Yamashiro et al. 2008). Fig. 5 shows an example of the sequence photographs obtained from the video image. The photographs show the process of the spray transportation. From the photographs, it is understood that a large wave run-up results in a large number of spray, and then the spray is transported by a strong wind like a white mist. Needless to say, undetectable much smaller spray and salt particles causing the salt damage in the area are transported and diffused to more wide area by wind. And it is easily predicted that such smaller salt particles increase as visible spray increases. Therefore, the resident in this area have been troubled by the damages to the houses, the cars, the garden plants, etc. from the transported salt water. According to the resident, the spray sometimes falls like a light rain on the road about $300 \mathrm{~m}$ away from the breakwater (see Fig. 3). 

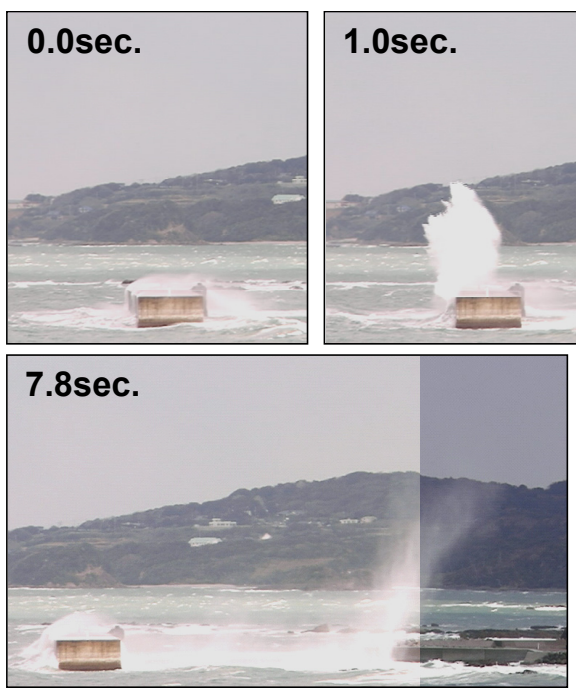
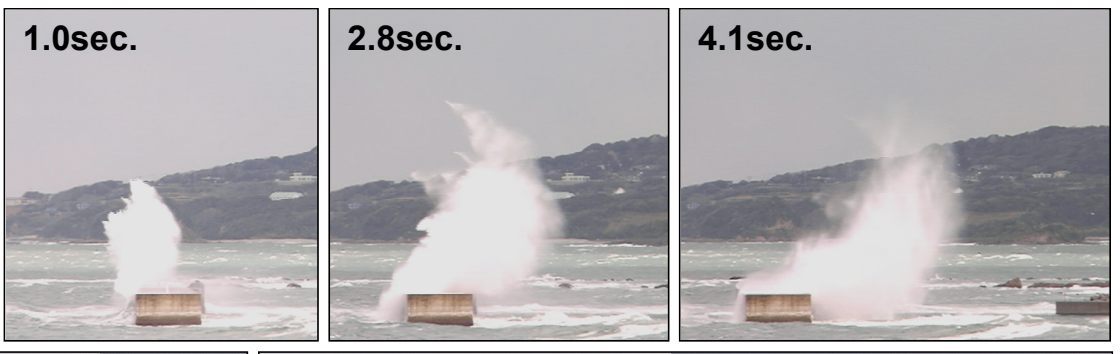

13.0sec.

Figure 5. Run-up and spray transportation recorded by digital video cameras.

\section{MEASURES TO REDUCE SEA SPRAY}

In the case of this fishing port, the local government proposed the following three plans to cope with salt damage in compliance with the wishes of residents: (a) covering the front face of the breakwater with wave dissipating blocks, (b) construction of a low-crested offshore breakwater of wave dissipating blocks in the further offing, (c) construction of an artificial reef in front of the breakwater. These plans aim to reduce the height of waves hitting the breakwater because it is difficult to reduce the seawater spray and sea salt particles directly. The cross sections of proposed plans were designed in consideration of the stability for the design wave and the design water level, the construction cost, the influence on the fishery, the safety of the navigation of fishing boats and the surrounding environment, etc.

\section{Breakwater covered with wave dissipating blocks}

In this plan, the existing breakwater will be covered with 40 tons type wave dissipating blocks. Fig. 6 shows the cross section of this plan. The wave dissipating blocks are fully installed to the top of the crown. This plan is superior to other plans in ease of construction and the cost. Besides, the blocks can reduce the reflected waves from the existing vertical wall. The expected demerit of this plan, however, is that entrance of the fishing port becomes narrower due to the blocks installed into the both sides of the existing breakwater.

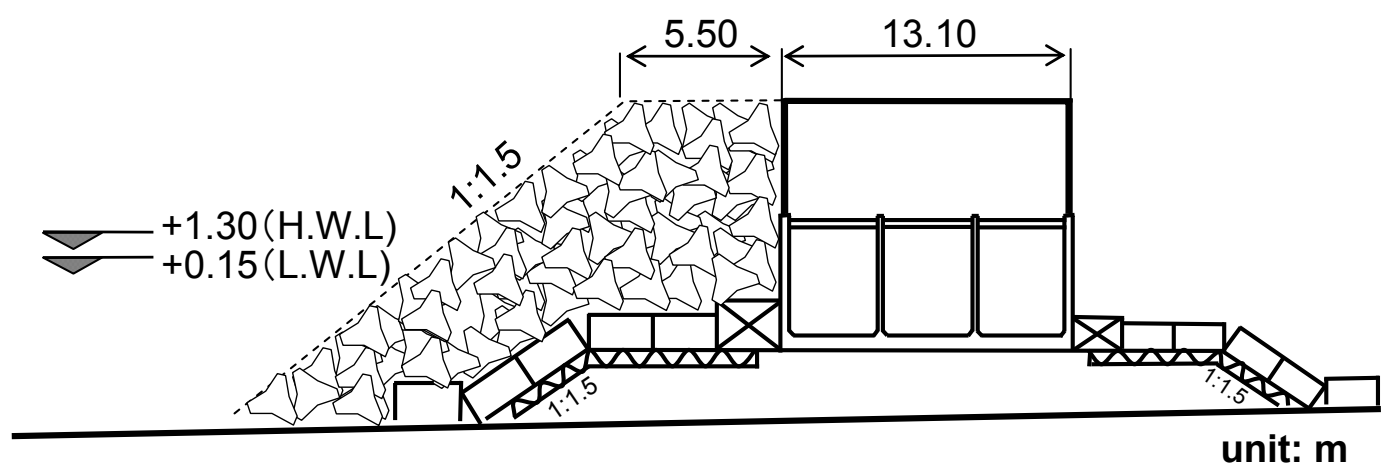

Figure 6. Cross section of breakwater covered with wave dissipating blocks (Plan(a)).

\section{Low crested breakwater}

In this plan, a wave absorbing breakwater will be constructed with 40 tons type wave dissipating blocks. The crest elevation of the breakwater was set at the low water level in order to lower construction costs. Fig. 7 shows the cross section of the breakwater. The low crested breakwater 
reduces the incident wave heights to attenuate the violent wave run-up at the existing vertical breakwater.

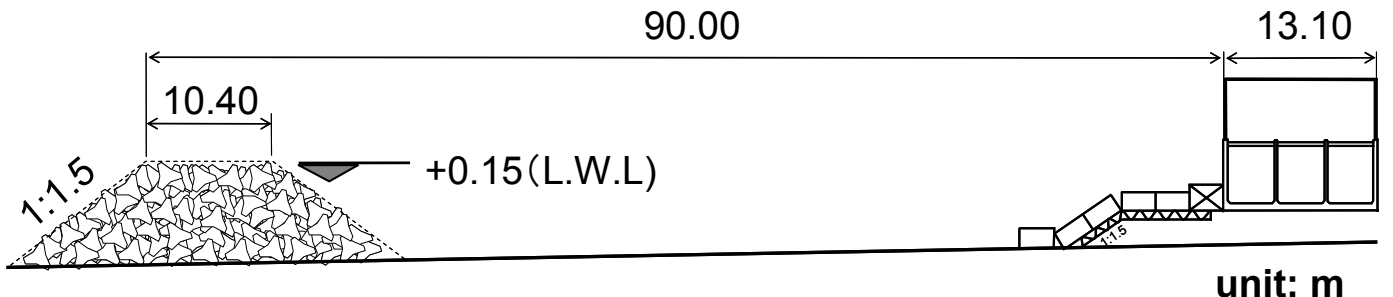

Figure 7. Cross section of low crested breakwater (Plan(b)).

\section{Artificial reef}

An artificial reef was selected as third plan because similar reefs had been applied at many points along the coast near Waku fishing port. The artificial reef is an impermeable reef. Fig. 8 shows the cross section of the artificial reef. The expected effect of the reef is the same as the effect of the abovementioned low crested breakwater. The construction cost of the reef, however, is estimated somewhat higher than the low crested breakwater.

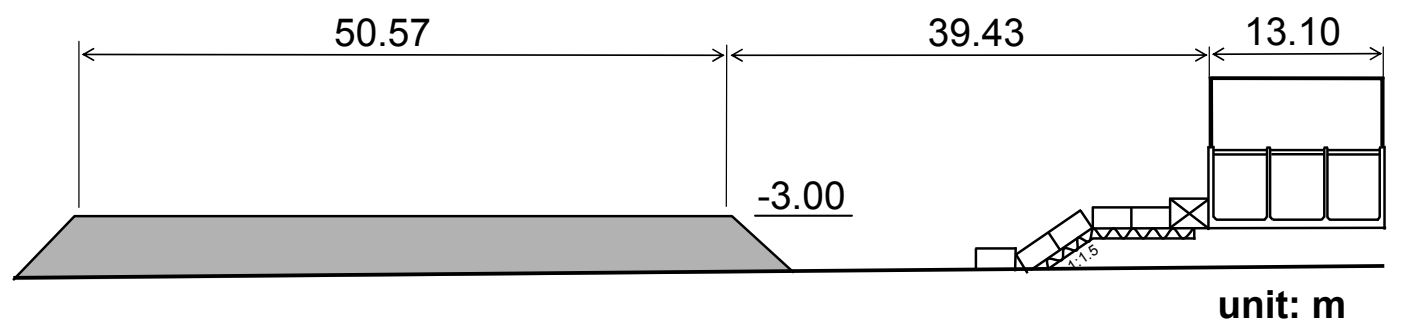

Figure 8. Cross section of artificial reef (Plan(c)).

\section{LABORATORY EXPERIMENTS}

In this study, the effects of the proposed three measures are investigated by conducting laboratory model experiments. Although the purpose is to clarify the reduction effect of the sea salt particles by the proposed measures, the sea salt particles can not be reproduced in the model experiments because the similarity law for the wind velocity on the generation of the sea salt particles due to the large wave run-up is not clear between the laboratory experiments and real fields. Thus, assuming that the quantity of sea salt particles is strongly related to that of detectable splash, which has much larger size than the sea salt particles, we estimated the effects of the measures by comparing the quantities of splash fallen behind the existing breakwater.

\section{Experimental setup}

As shown in Fig. 9, the experiments were conducted using a two-dimensional wind-wave flume ( $28 \mathrm{~m}$ long, $0.5 \mathrm{~m}$ deep, $0.3 \mathrm{~m}$ wide) with the function of absorbing the reflected waves. The flume has partially wide glass walls to make the observations better. The wind tunnel was installed from a little offshore of the breakwater to the end of the flume to avoid the influence of wind to the waves as much as possible. The models of the structures and the bottom topography were made with a scale of 1/70. Generating the wave and the wind at the same time, the spatial distributions of the splash quantity were measured with dozens of measuring boxes placed in line behind the breakwater model. The water surface oscillations were measured by two wave gauges as shown in Fig. 9 and the fluid motion in front of the breakwater such as wave run-ups or wave-overtoppings were recorded on a camcorder throughout the experiments. 


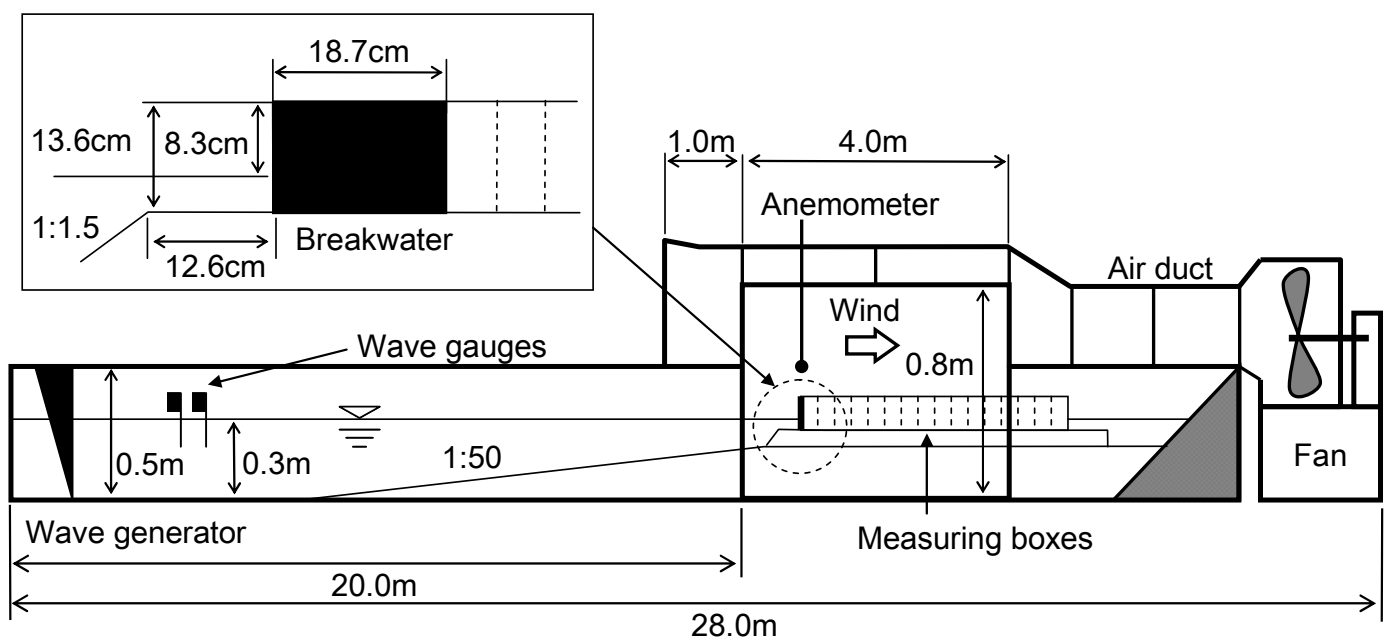

Figure 9. Experimental setup.

\section{Experimental conditions}

The wave condition was a random wave with the significant wave height $H_{1 / 3}$ of $3.8 \mathrm{~m}$ and the significant wave period $T_{1 / 3}$ of $9.2 \mathrm{~s}$ which was yielded in situ by a typhoon that hit this area on September 7, 2004. The reason we selected the random wave as the incident wave is that we really confirmed the severe situation on the site, which large wave run-ups and a large number of splashes and spray were caused by the wave. In the experiments, the incident wave was scaled down by Froude number $\left(H_{1 / 3}=5.4 \mathrm{~cm}, T_{1 / 3}=1.1 \mathrm{~s}\right)$ and two different wave trains were made from the same Bretschneider-Mitsuyasu type spectrum modified by Goda (2000). Fig. 10 shows the incident wave spectra separated from the water surface oscillations by using the method presented by GODA et al. (1976). It was confirmed that both incident waves agree well with the target spectrum.

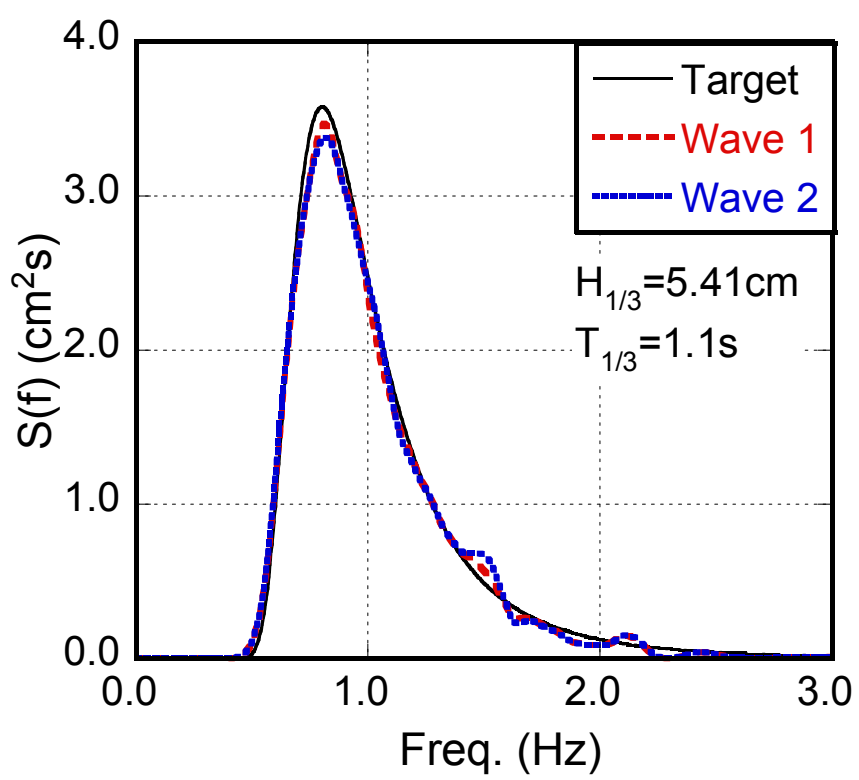

Figure 10. Incident wave spectra.

The wind velocities were changed from $3.0 \mathrm{~m} / \mathrm{s}$ to $6.0 \mathrm{~m} / \mathrm{s}$ at intervals of $1.0 \mathrm{~m} / \mathrm{s}$. The wind velocity in the experiments was represented with the mean wind velocity calculated in the range from the crown of the breakwater model to $50 \mathrm{~cm}$ above. As mentioned above, the similarity law for the wind velocity in the model experiment on the generation of the splashes due to the large wave run-up as well as the sea salt particles is not clear. Thus, in this study, the relative effects of the proposed measures were estimated under some wind velocity conditions. 
The duration generating the wave and the wind in each experiment was set 15 minutes and the measuring time of the splash quantity was 14 minutes excepting 1 minute from the beginning of wave generation. Since two different wave trains were made as the incident wave trains, the total measuring time as to a wind condition was 28 minutes, which correspond to about four hours in the real field.

Tidal level condition was set high water level throughout the experiments.

\section{RESULTS AND DISCUSSIONS}

\section{Experimental results}

We compared the wave-overtopping rates before the distributions of splash quantities are discussed. Fig. 11 shows the wave-overtopping rates for all cases. It is clear that the differences of the wave-overtopping rate due to structural types are very large and the wave-overtopping rate of the existing vertical breakwater is the largest among four structural types. Conversely, it can be said that the proposed measures can reduce the wave-overtopping rate. Above all, the covering with wave dissipating blocks is the most effective compared with other measures. The effect of wind, which the wave-overtopping rates for all structural types increase as the wind velocity increases, is also recognized obviously.

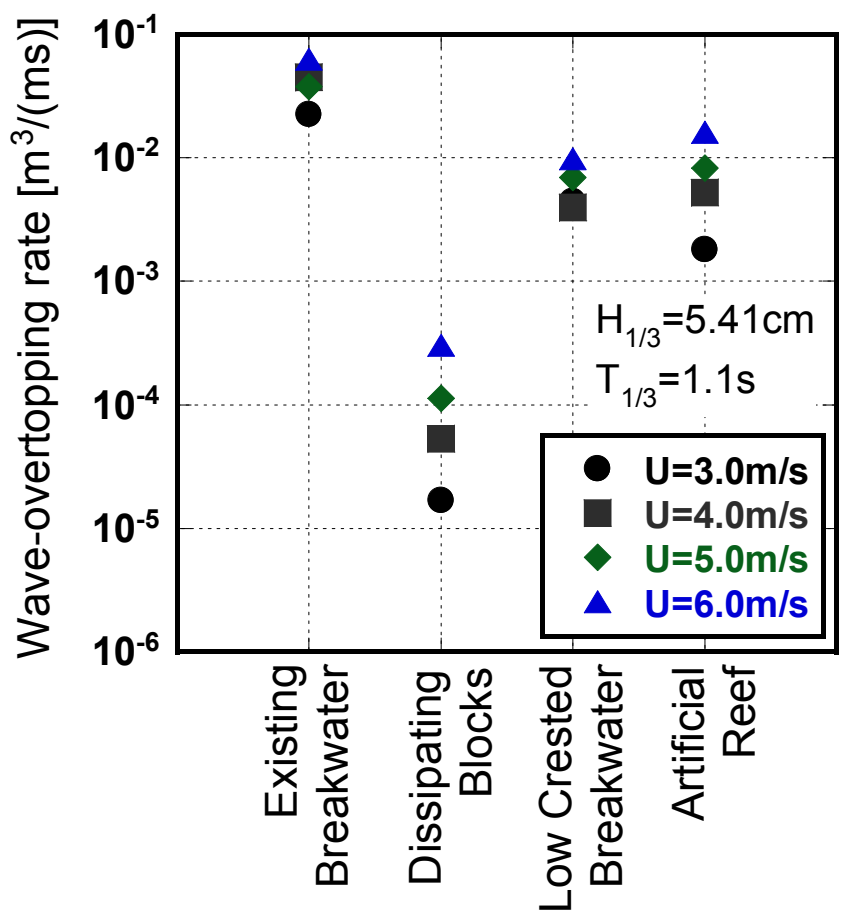

Figure 11. Comparison of wave-overtopping rate.

Fig. 12 shows the spatial distributions of the falling splash behind the breakwater. The falling splash $\boldsymbol{q}$ is indicated as the quantity per unit area and per second $\left(\mathrm{m}^{3} / \mathrm{m}^{2} / \mathrm{s}\right)$ and converted into the real scale. The distance from the face line of the breakwater is also converted into the real scale. The wind velocity shown in the figures, however, means the averaged value above the breakwater in the model scale. On the whole, since a lot of water directly flows into the box immediately behind the breakwater due to the wave-overtoppings, the water quantity at that position is particularly large. Besides that, the quantity of the falling water remarkably decreases with the distance from the breakwater. As the wind velocity increases from $3.0 \mathrm{~m} / \mathrm{s}$ to $6.0 \mathrm{~m} / \mathrm{s}$, however, the splash increases in every structure type. This result means that a large quantity of the splash, spray and sea salt particles diffuse to a wide area due to the strong wind. 

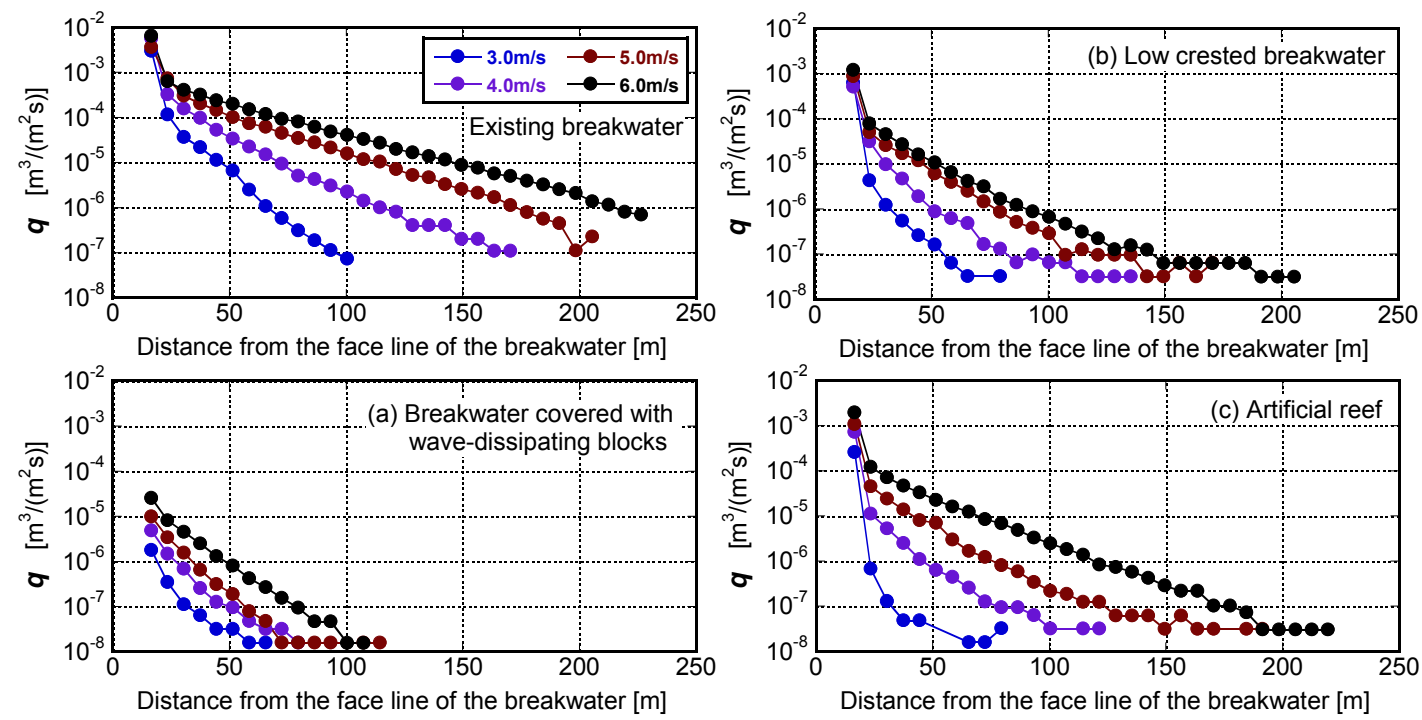

Figure 12. Spatial distributions of falling splash behind the breakwater.

\section{Reduction effects of splashes}

Fig. 13 shows the same spatial distributions of the falling splash as the results shown in Fig. 12 again. The distributions, however, are rearranged as to the wind velocity in order to make the comparison of the reduction effects easier. From this figure, it is understood that each measure can obviously reduce the splash generated at the existing breakwater. When the wind velocity is relatively small, there are hardly differences of reduction effects among the three measures. The large differences, however, appear as the wind velocity increases. Covering with the wave dissipating blocks is much more effective than other two measures. The results of the low crested breakwater and the artificial reef are almost the same by chance in all wind velocity conditions.
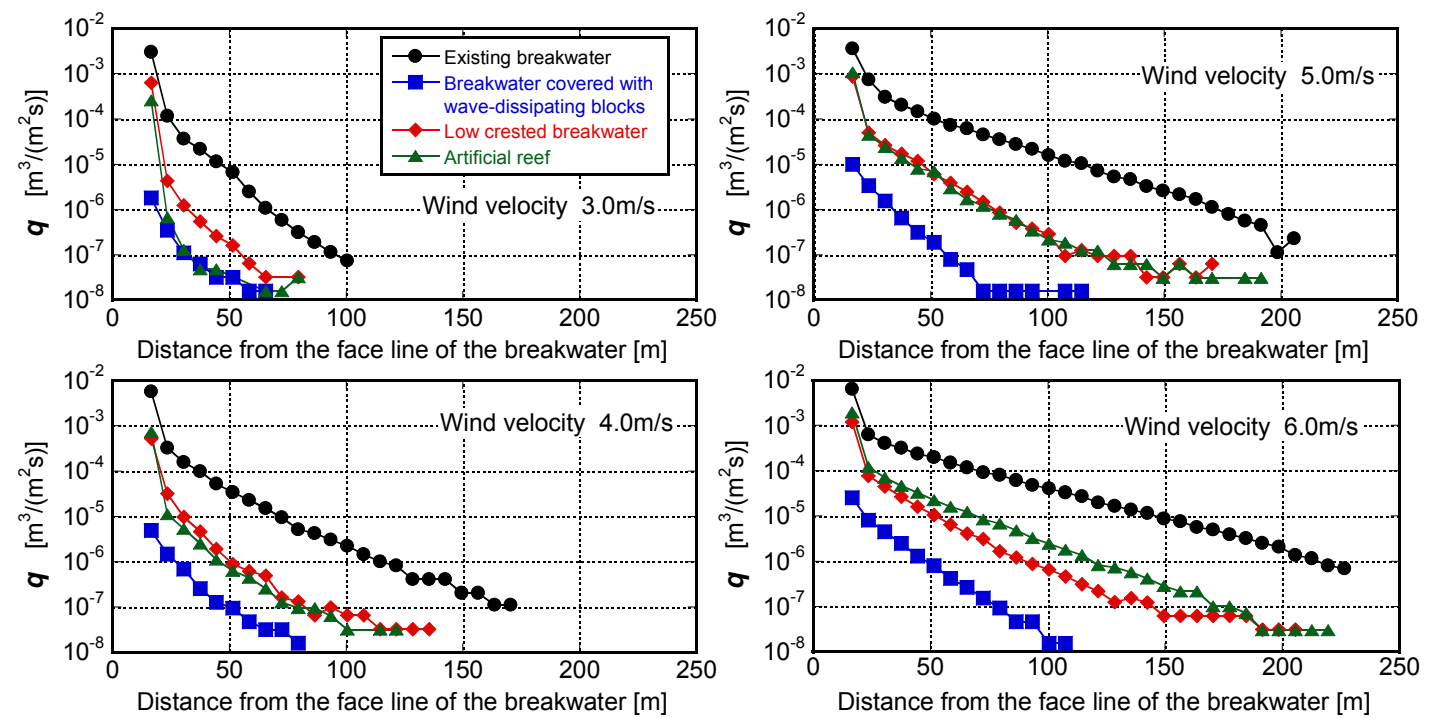

Figure 13. Comparison of spatial distributions of falling splash.

Fig. 14 shows the spatial distributions of the ratios of the splash quantity. $\boldsymbol{q}_{0}$ means the splash quantity for the existing breakwater and $\boldsymbol{q}$ means that for the measures. When the wind velocity is small, the distributions are somewhat concave. The increases of the ratios in the region far from the breakwater, however, are unreliable because the detected splash quantity in the region is almost the measuring limit in the experiments and the values are not entirely accurate. In the region where the splash quantity is larger than $10^{-7} \mathrm{~m}^{3} /\left(\mathrm{m}^{2} \mathrm{~s}\right)$ in Fig. 13, the ratios of the splash quantity shown in Fig. 14 
are probably reliable. Fig. 15 shows $\boldsymbol{q} / \boldsymbol{q}_{0}$ versus wind velocity at a location $50 \mathrm{~m}$ away from the front face of the vertical breakwater. Figs. 14 and 15 indicate that both the low crested breakwater and the artificial reef reduce the falling splash quantity to $1 / 10$ or less in a wide area behind the breakwater compared with the existing breakwater and the covering with wave dissipating blocks can reduce the splash to much little $1 / 100$ or less. The low crested breakwater and the artificial reef can reduce the incident wave height. However, since the existing breakwater still has vertical face, the wave run-up and consequent seawater splash easily occur compared with the covering with wave dissipating blocks. If both the low crested breakwater and the artificial reef have higher crown heights, these structures would display much higher effects of splash reduction. On the other hand, although the covering with the wave dissipating blocks is very effective to reduce the splash, if covering is not enough, it is feared that the wave run-ups and the splashes easily occur at the vertical face partially not covered with the wave dissipating blocks.
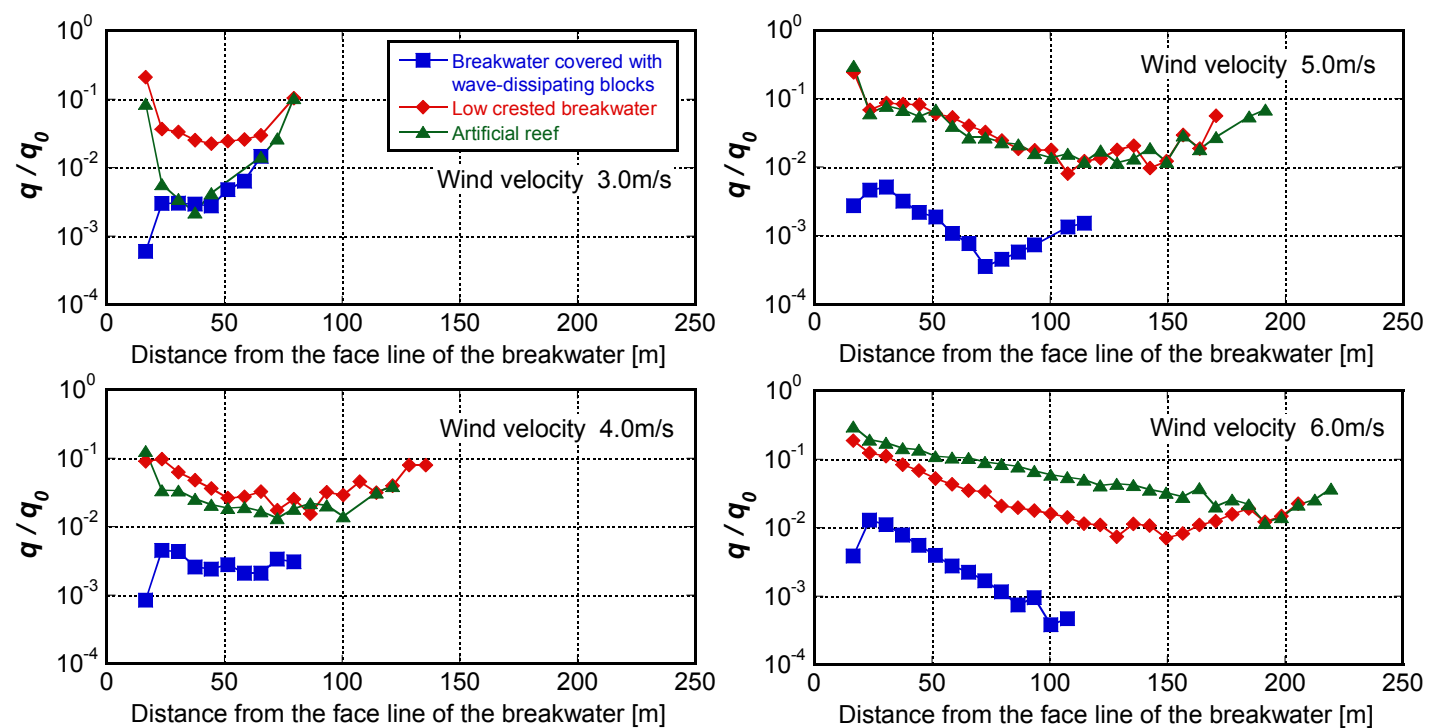

Figure 14. Spatial distributions of ratio of splash quantity $q / q_{0} ; q_{0}$ splash quantity for the existing breakwater, $q$ splash quantity for the measures.

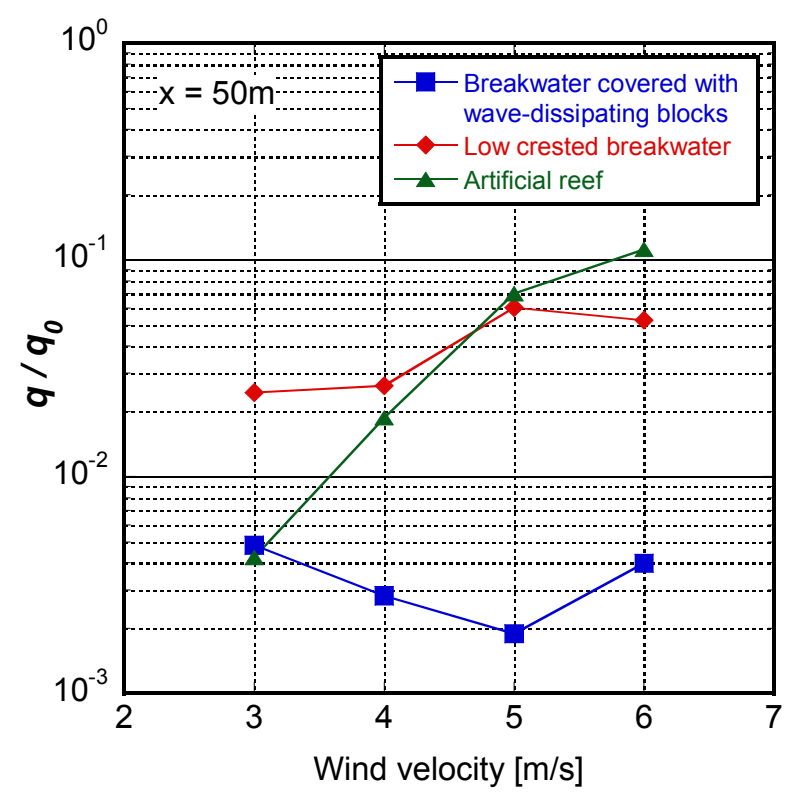

Figure 15 . Ratio of splash quantity $q / q_{0}$ versus wind velocity at $x=50 \mathrm{~m}$ behind the breakwater. 


\section{CONCLUSIONS}

In this study, to compare the effects of the three structural types, (a) the covering the front face of the breakwater with wave dissipating blocks, (b) the construction of a low-crested offshore breakwater of wave dissipating blocks in the farther offing, (c) the construction of an artificial reef in front of the breakwater, which are proposed to reduce a large number of sea salt particles generated at the existing vertical breakwater, comparative model experiments on the distributions of the splash quantity behind the breakwater were conducted by using a wind-wave flume. As the results of the experiments, it was found that splashes and spray easily occur at vertical walls even if incident wave heights are reduced with a low crested breakwater or an artificial reef. In contrast, fully covering the front face of the breakwater with wave dissipating blocks is greatly effective in reducing the splashes and spray generated at the vertical wall. Thus, these comparative experiments finally led to a conclusion that the breakwater covered with wave dissipating blocks is the most effective measure among the proposed plans.

On the basis of the conclusions, the covering with the wave dissipating blocks was actually applied to the real breakwater and the construction completed in summer 2009. In this study, assuming that the quantity of sea salt particles, which is main cause of salt damage around Waku fishing port, is strongly related to the quantity of larger splash, we conducted comparative model experiments. Although, the experimental results showed that the covering with the wave dissipating blocks is the most effective measure against the generation of a large quantity of the splash among proposed three measures, its quantitative effect is still unclear. To clear the quantitative reduction effect of the sea salt particles by the covering the existing vertical breakwater with wave dissipating blocks, we are going to conduct field observations on the quantity of the sea salt particles at Waku fishing port.

\section{ACKNOWLEDGMENTS}

The authors would like to thank the members of Waku Fishermen's Cooperative and the municipal officials in Shimonoseki City for their help in this study. The authors express also our grateful thanks to Mr. Takeshi Kashima, Mr. Hiroki Hashimoto and Mr. Takaya Ono, who were master course students and devoted time to the model experiments.

\section{REFERENCES}

EurOtop overtopping manual, 2007. Wave overtopping of Sea Defences and Related Structures: Assessment Manual, eds. T. Pullen, N. W. H. Allsop, T. Bruce, A. Kortenhaus, H. Schüttrumpf and J. W. Van der Meer, http://www.overtopping-manual.com.

Goda, Y. and Y. Suzuki. 1976. Estimation of Incident and Reflected Waves in Random Wave Experiments, Proceedings of $15^{\text {th }}$ International Conference on Coastal Engineering, ASCE, 828845.

Goda, Y. 2000. Random seas and design of maritime structures, World Scientific, Advanced Series on Ocean Engineering, Vol. 15.

The Overseas Coastal Area Development Institute of Japan. 2002. Technical standards and commentaries for port and harbour facilities in Japan, $600 \mathrm{pp}$.

Yamashiro, M., A. Yoshida and K. Murakami. 2008. Effect of wind on landward transportation of spray generated by wave overtopping at vertical breakwater, Proceedings of $31^{\text {th }}$ International Conference on Coastal Engineering, ASCE, 3084-3096. 